Review

\title{
Disability and Health: A Research Agenda
}

Hasheem Mannan ${ }^{1,2}$ and Malcolm MacLachlan 2,3

${ }^{1}$ Nossal Institute for Global Health, University of Melbourne, Victoria, Australia; E-Mail: hmannan@unimelb.edu.au; Tel.: +61 390356184; Fax: +61 393476872

${ }^{2}$ Centre for Global Health \& School of Psychology, Trinity College Dublin, Dublin, Ireland;

E-Mail: mlachlan@tcd.ie (M.M.)

${ }^{3}$ Centre for Rehabilitation Studies, Stellenbosch University, South Africa

\section{How to Cite this Article}

Mannan, H., \& MacLachlan, M. (2013). Disability and Health: A Research Agenda. Social Inclusion, 1(1), 37-45.

\section{Acknowledgement}

This Review was published by Librello, Social Inclusion's former publisher.

\begin{abstract}
About the Journal
Social Inclusion is a peer-reviewed open access journal which provides academics and policy-makers with a forum to discuss and promote a more socially inclusive society. The journal encourages researchers to publish their results on topics concerning social and cultural cohesiveness, marginalized social groups, social stratification, minority-majority interaction, cultural diversity, national identity, and core-periphery relations, while making significant contributions to the understanding and enhancement of social inclusion worldwide.
\end{abstract}

www.cogitatiopress.com/socialinclusion

Editor-in-Chief

Professor UIf R. Hedetoft, Faculty of Humanities, University of Copenhagen, Denmark

Managing Editor

Mr. António Vieira, Social Inclusion, Cogitatio Press, Portugal 


\title{
Disability and Health: A Research Agenda
}

\author{
Hasheem Mannan ${ }^{1,2, *}$ and Malcolm MacLachlan ${ }^{2,3}$ \\ ${ }^{1}$ Nossal Institute for Global Health, University of Melbourne, Victoria, Australia; \\ E-Mail: hmannan@unimelb.edu.au; Tel.: +61 390356184; Fax: +61 393476872 \\ ${ }^{2}$ Centre for Global Health \& School of Psychology, Trinity College Dublin, Dublin, Ireland; \\ E-Mail: mlachlan@tcd.ie (M.M.) \\ ${ }^{3}$ Centre for Rehabilitation Studies, Stellenbosch University, South Africa \\ * Corresponding author
}

Submitted: 12 April 2013 | In revised form: 29 July 2013 | Accepted: 30 July 2013 |

Published: 12 August 2013

\begin{abstract}
Disability is not a 'health problem'; however some people with disabilities do have increased health needs, and all people with disabilities have the same right to access health services as others. The number of people living with disabilities is increasing, due partly to increasing numbers of people living with the consequences of chronic communicable and noncommunicable diseases. Based on recommendations of the World Report on Disability, which provides the parameters for research, this paper sets out a research agenda calling for a considerable research programme on social, civil, and economic impacts of living with disability, arising from whatever cause, including communicable and non-communicable diseases; significant global health policy revisions; identification of constraints and facilitators in access to healthcare for people with disabilities; development of a robust evidence base for implementing the new guidelines on community-based rehabilitation; innovations in addressing human resource challenges faced by disability and rehabilitation service-providers; development of enabling technologies that focus on individuals' aspirations and social gain; preparedness for responding to the needs of people with disabilities in disaster situations; and the application of disability metrics to strengthen health systems.
\end{abstract}

Keywords: disability; health metrics; health policy; public health; research agenda

\section{Introduction}

There is an urgent need to improve the collection, analysis, synthesis and dissemination of data on disability in a way that is both accurate and comparable across different settings, countries and populations [1].
In the early 2000s, the World Health Organisation (WHO) reconceptualised disability-moving away from the individualised deficit 'medical model' and embracing the idea of disability as an interaction of personal and societal factors [2], where its most salient features are activity limitations and participation restrictions, 
rather than unalterable diagnostic categories or bodily impairments (Figure 1). This conceptualisation provided support for the impetus for people with disabilities to enhance their own activity and their participation in society; encouraging emancipatory initiatives and contributing to the idea that disability is a human rights issue. While disability is not a 'health problem', some people with disabilities do have increased health needs associated with their disability, and all people with disabilities have the same right to access health services as everyone else [3]. The number of people living with disabilities is likely to increase, due in part to a greater number of people living with the consequences of chronic communicable and non-communicable diseases. If we are to seriously address the health rights and needs of people with disabilities, what are the critical research challenges that need to be addressed in the next decade? We recognise that disability and health is a very broad topic; ranging across illness, disease and rehabilitation to wellbeing, positive living and empowerment. While we have an interest in highlighting here some service-related aspects of health, we also note that research on health has to be much broader than this.

Previously, research questions have been generated by expert opinion exercises that included persons with disabilities and their representative organizations $[4,5]$. We recognise that the health needs of persons with disabilities represent only one component of their diverse service entitlements. However, this research agenda provides a conceptual framework, not only to address the very legitimate right to health of persons with disabilities [6], but also offers an opportunity to leverage greater research attention for aspects of community based rehabilitation which are complementary to health, such as assistive technology and natural disaster management. The research agenda outlined here has been presented to and incorporates various stakeholders including persons with disabilities, their representative organisations and various government ministries responsible for rights of persons with disabilities at forums such as AfriNead (African Network for Evidence to Action on Disability) [7] and the dissemination workshops of Project EquitAble across South Africa, Malawi, Namibia, and Sudan [8].

The United Nations Convention on the Rights of Persons with Disabilities (UNCRPD) [3] has been the most widely and rapidly ratified United Nations Convention, entering into international law in 2008. The response from the health sector has also been impressive: WHO, International Labour Organization (ILO), United Nations Educational, Scientific, and Cultural Organization (UNESCO), and International Disability and Development Consortium (IDDC) collaborated on Guidelines for Community Based Rehabilitation [9], seeking to bring principles of common practice to this widely used philosophy; but also, importantly, recognising the cross-sectoral inter-dependency of such programmes (Figure 2). In so doing, these Guidelines are one of the clearest expositions of the Bamako Call to Action on Research for Health for a much broader perspective on research for health [10].

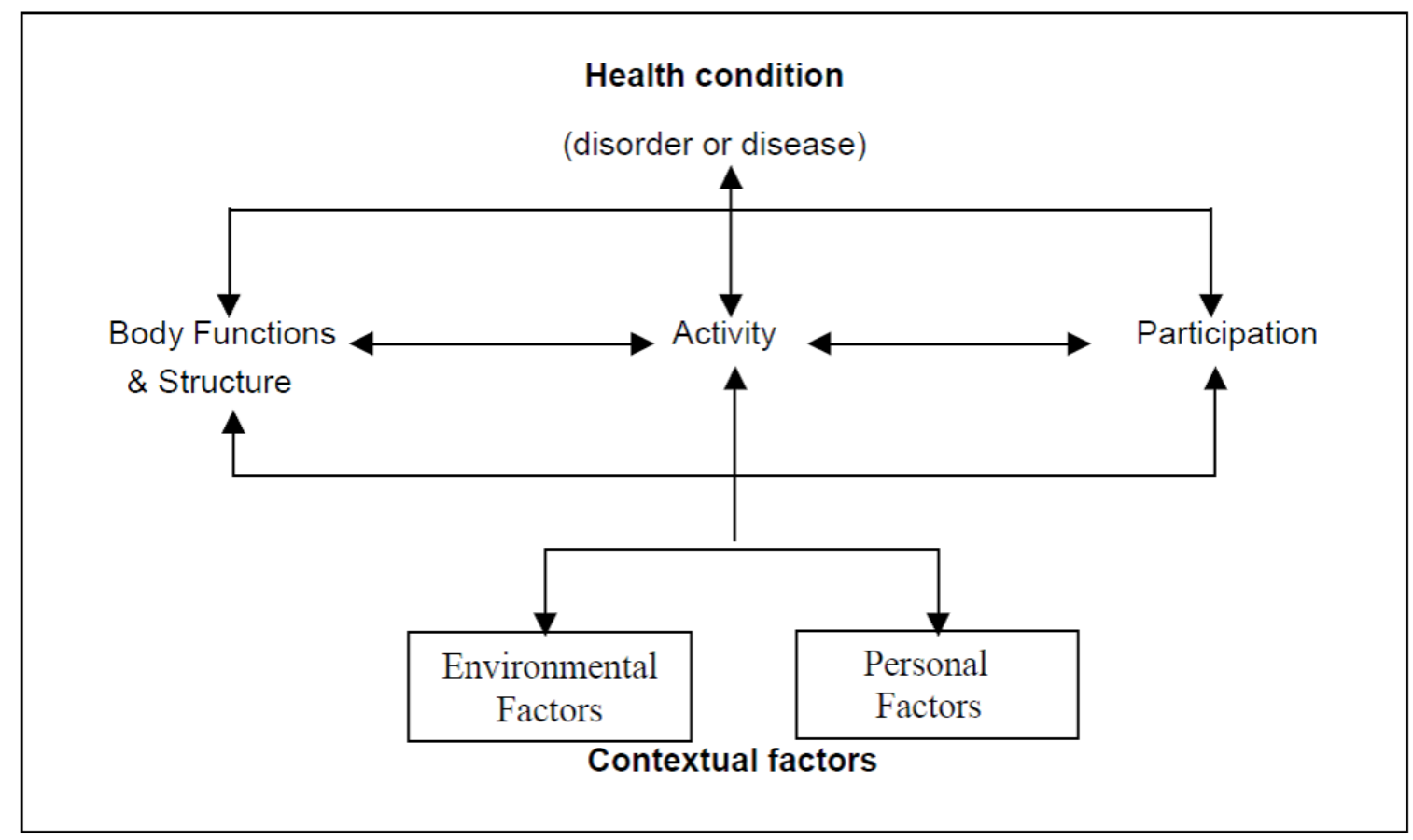

Figure 1. Model of disability that is the basis of International Classification of Functioning, Disability and Health (ICF). 


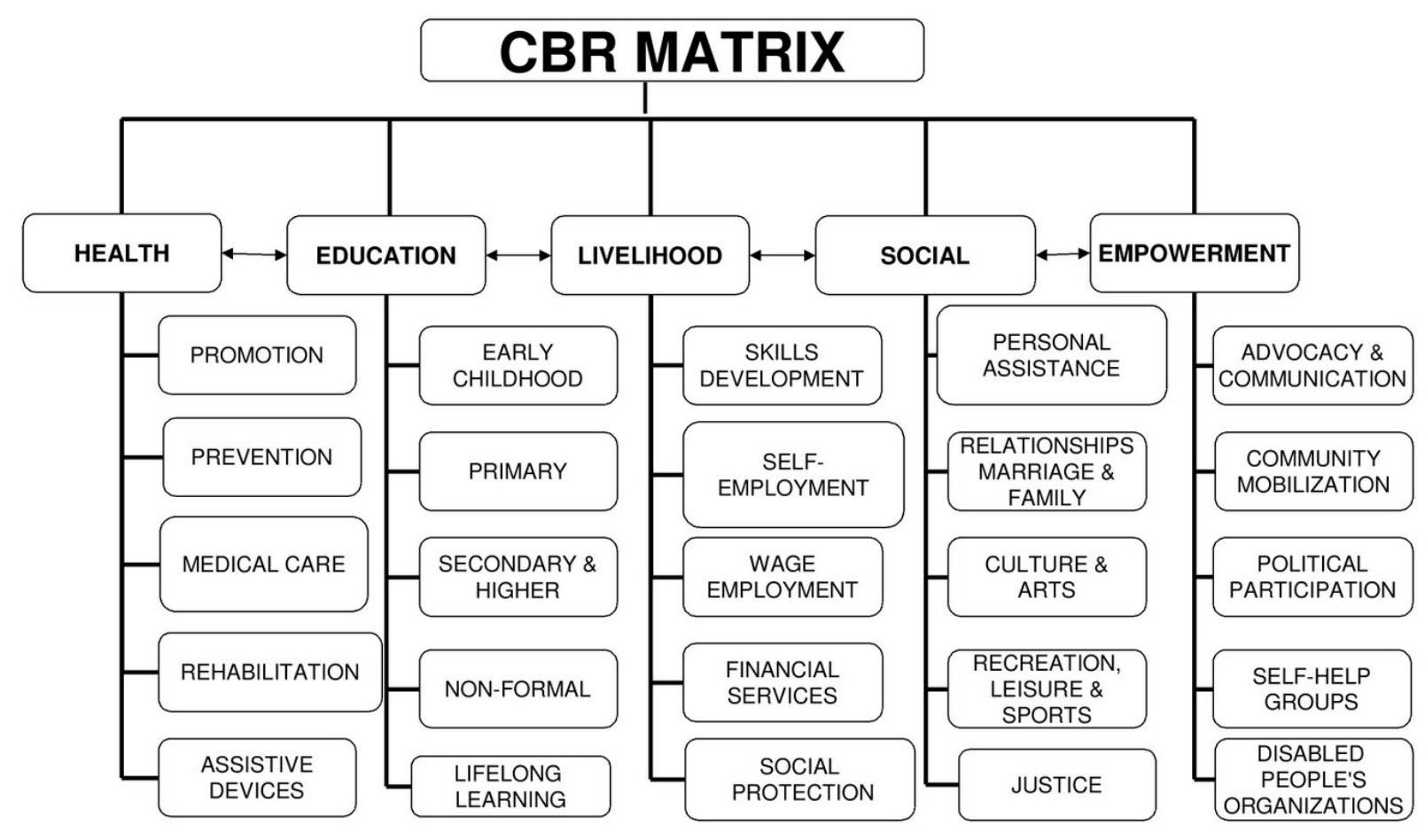

Figure 2. Community based rehabilitation matrix.

In 2011, WHO and the World Bank published the first ever World Report on Disability, estimating that $15 \%$ of the world's population-over 1 billion peopleexperience some type of disability; with $80 \%$ of these people living in low-income countries [11]. The report is a sobering 'state of the knowledge', identifying some of the major challenges that must be addressed (Table 1). Disability is also the focus for the United Nations Children's Fund (UNICEF) 2013 State of the World's Children Report [12]. All of these policy initiatives recognise the lack of and need for a greatly enhanced evidence-base. During the last decade, there has been a radical revision in the conceptualisation of disability, a crescendo of international policy initiatives and reports, and an increasing number of people living with disability. All of this calls for an ambitious research agenda, addressing the interface between disability and health, for the decade ahead. We generate a list of research topics, in line with the nine umbrella recommendations made in the World Report on Disability, which could enable fulfilling the potential for the above initiatives to improve the health and lives of perhaps the world's largest marginalised group. Empirically-derived research priorities-especially those incorporating the participation of marginalised groups $[4,5]$ - constitute a critical contribution to research agenda setting in this area. However they should not be seen as the 'last word'. There is also a place for conceptually derived agenda, especially if they can complement the recent World Report on Disability, which other research agenda setting pre-dates. Our contribution is therefore offered as complimentary and hopefully encouraging of further interest, debate and research in this critical area, which requires different perspectives and ideas to maintain its vibrant nature.

\section{Public Health}

Public health has traditionally focused on the prevention of mortality, morbidity, and disability [13] and eschewed the challenge of helping people with disabilities to live full lives [14]. Medical technologies and public health interventions have beckoned what Oeffinger et al. [15] describe as-an epidemic of survival; escaping death through living with disability. This may have been truer in richer countries, but is becoming increasingly the case in poorer countries too.

Table 1. Main recommendations of the World Report on Disability.

Enable access to all mainstream systems and
services
Invest in programmes and services for people
with disabilities
Adopt a national disability strategy and plan of
action
Involve people with disabilities
Improve human resource capacity
Provide adequate funding and improve
affordability
Increase public awareness and understanding
about disability
Improve the availability and quality of data on
disability
Strengthen and support research on disability


A vast majority of the leading 20 health conditions associated with disability are non-communicable diseases [11]. For instance, disabilities arising from diabetes complications can lead to productivity loss and life-long care $[16,17]$. Also, the increased availability of antiretroviral drugs (ARVs) to treat HIV/AIDS will make it a lifespan condition; with many people living with HIV, including children, developing different types of impairments and functional limitations [18], as well as participation restrictions $[19,20]$. Thus, a considerable research programme on social, civil and economic impacts of living with disability arising out of both communicable and non-communicable diseases is now needed.

\section{Health Policy}

Policies need to specifically promote the human rights of people with disabilities - this obligation is founded on international human rights standards. The UNCRPD [3] established a legally-binding human rights and moral context for action on health as a human right for persons with disabilities. The UNCRPD stipulates that 'States Parties undertake: To take into account the protection and promotion of the human rights of persons with disabilities in all policies and programmes' (art. 4) [3]. As the UNCRPD is about rights of citizenship, empowerment and wellbeing, we would see it all as relevant to our broad conceptualisation of health; while noting that particular Articles refer to health service provision, such as Articles on 'Respect for privacy' (art. 22), 'Health' (art. 25), and 'Habilitation and rehabilitation' (art. 26). Although the UNCRPD is now enshrined in international law-requiring both national policies and international aid policies to align with it-its provisions do not magically appear in such documents. Such policies have proved quite resistant to the inclusion of previous UN Conventions aimed at addressing marginalisation $[21,22]$. However, health policies explicitly built on equity, that take steps to address specific exclusionary practices, will prioritise vulnerable and marginalised groups $[23,24]$, while those that simply embrace 'all people', or 'all citizens', may implicitly privilege 'some' over others. A programme of research and policy revision is needed that can help to translate high-level declarations into specific policy commitments in national policy level documents $[25,26]$. Research must address not just what form of words is needed but also how persons with disabilities can advocate for and influence the policy revision process both in health and Poverty Reduction Strategy Papers, which set the broader national policy context in which health initiatives must work [27].

\section{Access to Healthcare}

While there has been considerable recognition in healthcare of the importance of equity, this has not been the case for accessibility; yet health services cannot hope to be equitable if they are not equally accessible. Persons with disabilities are among those who have the greatest difficulties accessing services; both the constraints and facilitators require a health systems approach that can trace and strengthen 'pathways to care' and the related services that support this $[28,29]$, such as transport and education. Due to the broad range of health care needs and their difficulties accessing health services, research agenda documenting the experiences of persons with chronic diseases and disabilities would serve as a good probe of the effectiveness of health systems [6].

\section{Community-Based Rehabilitation}

The Community-Based Rehabilitation: CBR Guidelines [9] come after decades of the application of CBR in a myriad of fashions, through varied mechanisms and in hugely differing contexts. In consequence, we have very little idea of what works well, where it works, how or why [30]. With the Guidelines already being implemented through quite different interpretations, we urgently need to establish a programme of implementation that oversees and allows for organisational, country and contextual differences, but also facilitates comparable data collection, through the establishment of a range of 'common goods' concerned with CBR training, support, monitoring, evaluation and research. The establishment of a Global Programme of Research on Disability and Inclusive Development would be an effective mechanism to achieve this.

\section{Human Resources for Health}

WHO's Maximizing Positive Synergies Collaborative Group [31] noted a global deficit of trained health workers of over 4 million, but failed to acknowledge or address the significant human resources for health (HRH) crisis especially in the provision of services for people with disabilities [32]. It is now widely accepted that promoting and protecting health requires the effective interaction of various public service sectors, such as health, social welfare and education. The CBR Guidelines also require a skill mix not available in any existing profession, indicating the need to develop a new alternative cadre that could embrace this skill mix and support existing professions, but through a much shorter and more focused training. Indeed the World Report on Disability [11] notes that-developing standards in training for different types and levels of rehabilitation personnel can assist in addressing resource gaps (p. 266), particularly in impoverished countries, where there is a proportionally high number of persons with disabilities. Research on health system strengthening and the necessary human resources to achieve it, should therefore reflect an intersectoral ethos. Until now, much of the research on the effectiveness of alternative cadres has focused on technical specialists. Future research needs to focus 
on generalists, who have the potential to braid together inter-sectoral aspects of health and therefore make a very important human resources contribution to overall health system strengthening, thus enhancing the accessibility of services.

\section{Enabling Technologies}

Technologies from wheel chairs to prosthetic limbs have accelerated in complexity and sophistication in recent years, but sometimes technical advances have exceeded the personal gains of their users, and failed to overcome participation restrictions [33]. Stigma, including self-stigma, remains a problem that prevents people achieving their full potential. However, around $90 \%$ of people in low-income countries who need assistive/enabling technologies are unable to acquire these technologies [11]. Access to even simple tech- nologies can have dramatic effects and has been shown to be predictive of enjoyment of human rights and increased capabilities, even in very poor settings [34]. A great deal more research on appropriate and affordable enabling technologies is now needed, along with how technological advances can support personally meaningful gains.

\section{Disability and Disaster Response}

Handicap International [35] has sought to make responses to disasters much more inclusive of persons with disabilities. They conceptualise the relationship between some of the key elements being expressed as: Disaster Risk $=$ Hazard $\times$ Vulnerability $/$ Capacity. The Humanitarian response sector is increasingly recognising the need for evidence-based practice, a need being addressed, at least in part, by Evidence Aid [36].

Table 2. Census questions on disability endorsed by the Washington Group.

\section{Introductory Phrase}

The next questions ask about difficulties you may have doing certain activities because of a HEALTH PROBLEM

1. Do you have difficulty seeing, even if wearing glasses?

a. No - no difficulty

b. Yes - some difficulty

c. Yes - a lot of difficulty

d. Cannot do at all

2. Do you have difficulty hearing, even if using a hearing aid?

a. No - no difficulty

b. Yes - some difficulty

c. Yes - a lot of difficulty

d. Cannot do at all

3. Do you have difficulty walking or climbing steps?

a. No - no difficulty

b. Yes - some difficulty

c. Yes - a lot of difficulty

d. Cannot do at all

4. Do you have difficulty remembering or concentrating?

a. No - no difficulty

b. Yes - some difficulty

c. Yes - a lot of difficulty

d. Cannot do at all

5. Do you have difficulty (with self-care such as) washing all over or dressing?

a. No - no difficulty

b. Yes - some difficulty

c. Yes - a lot of difficulty

d. Cannot do at all

6. Using your usual (customary) language, do you have difficulty communicating, for example understanding or being understood?
a. No - no difficulty
b. Yes - some difficulty
c. Yes - a lot of difficulty
d. Cannot do at all 
Table 3. Research challenges for disability and health.

Public Health

Health Policy

Healthcare Access

Community Based

Rehabilitation

Human Resources

for Health

Enabling Technologies

Disability and Disaster Response

Disability Metrics
Identifying public health approaches that enhance participation of persons with disabilities in their economic, civic, social and political life.

Revising existing policies and development of new policies that address the human rights of people with disabilities, and including people with disabilities in these processes.

Identifying the constraints and facilitators for access to health care, and incorporating these into a systems-strengthening approach.

Developing a global programme on disability and inclusive development that will facilitate the collection of comparable data and provide 'common goods' for CBR training, support, monitoring, evaluation and research.

Development of a new cadre for community based rehabilitation, with a broad skill mix and an ethos of evidence-based practice, whose practice can contribute to a developing evidence base.

Developing contextually appropriate and affordable enabling technologies that can facilitate personally meaningful gains for their users.

Establish and evaluate systems and personal coping responses to disaster situations for people with disabilities, chronic illness and the elderly.

Develop and apply standardised disability metrics that can be used to strengthen over-all health systems.
While this is a high profile area, very little research has addressed just how persons with disabilities can cope with and survive disaster situations, which of course includes many elderly people and people with chronic illnesses. Many government agencies are failing to adequately plan for, as well as include, persons with disabilities in disaster management processes; this creates significant inequities in access to immediate responses, as well as long-term recovery resources, for those people who have disabilities prior to the occurrence of the disaster as well as those who acquire a disability as a result of the disaster [37].

\section{Disability Metrics Strengthening Health Systems}

The discussion paper of the World Conference on Social Determinants of Health [38] states that-to monitor health inequities and social determinants, data must be separated, analysed, and compared-or-disaggregated according to the main factors known to be associated with health inequities; these social-stratifiers include disability. The old adage-what gets measured, gets done-indicates the importance of establishing easy to use and widely adopted measures of disability. The approach to disability measurement taken by Washington Group (Table 2) has also been incorporated into the UN Principles and Recommendations for Population and Housing Censuses [39]. In fact, the health service experiences of persons with disabilities could be an excellent probe of the degree of equitable access to health services, because if persons with disabilities are receiving appropriate and timely care and support, then it is likely that so too are other people [6].

\section{Conclusions}

Table 3 summarises the themes that require an upscaling of research if we are to address the healthrelated needs, rights and aspirations of the estimated one billion people who have a disability. Many of the types of problems faced by people with disabilities are similar across different settings, but their extent differs massively; often being life-threatening and usually life-diminishing in the context of extreme poverty. Thus, we have set out the above research agenda that calls for a considerable research programme on social, civil, and economic impacts of living with disability arising out of the full range of causes of disability, including communicable and non-communicable diseases; significant global health policy revisions; inquiry of constraints and facilitators in access to healthcare for people with disabilities; development of a robust evidence-base for implementing the new guidelines on community-based rehabilitation; innovations in addressing the human resource challenges faced by disability and rehabilitation service-providers; the development of enabling technologies that focus on individuals' aspirations and social gain; preparedness for responding to the needs of persons with disabilities in disaster situations; and the application of disability metrics to strengthen health systems. There is an urgent need to establish robust and generic indicators and metrics for disability, to address stigma and promote the participation of persons with disabilities, for the benefit of all. 
We need research that focuses not just on what to do, but also on how to do it; the organisational and systems factors that mediate such interventions, and the varied contextual factors that moderate outcomes. Community responses to disability should embrace an 'inclusive development ethos' where improved services and opportunities for some, go in tandem with the same aspirations for all. A collaborative global network of Centres of Excellence in Disability and Health, funded by pursuing competitive calls for proposals, such

\section{References}

1. World Health Organization. Disability-Report by the Secretariat. Sixty-Sixth World Health Assembly, Provisional Agenda Item 13.5 (A66/12; 11 March 2013). Geneva, Switzerland: WHO; 2013. Available from: http://apps.who.int/gb/ebwha/pdf_files/WHA66/ A66_12-en.pdf (accessed on 29 July 2013).

2. World Health Organization Classification, Assessment, Surveys and Terminology Team. International Classification of Functioning, Disability and Health: Final Draft. Geneva, Switzerland: WHO; 2001. Available from: http://www.sustainable-design.ie/arch/ ICIDH-2Final.pdf (accessed on 29 July 2013).

3. United Nations. Convention on the Rights of Persons with Disabilities and Optional Protocol. New York, NY, USA: United Nations; 2006. Available from: http://www.un.org/disabilities/documents/convention/ convoptprot-e.pdf (accessed on 29 July 2013).

4. Tomlinson M, Swartz L, Officer A, Chan KY, Rudan I, Saxena S. Research Priorities for Health of People with Disabilities: An Expert Opinion Exercise. Lancet. 2009;374(9704):1857-1862. doi:10.1016/S01 40-6736(09)61910-3.

5. Llewellyn G, Makuwira J, Madden R, Brentnall J, Lukersmith S, Mpofu E, Bundy A, Veitch C, Broom A. Developing a Disability and Development Research Agenda for Asia and the Pacific. Melbourne, Australia: CBM; 2010. Available from: http://www.addc.org.au/ content/resources/20100930-developing-a-disability-a nd-development-research-agenda-for-asia-and-the-pa cific/267 (accessed on 29 July 2013).

6. MacLachlan M, Mannan H, McAuliffe E. Access to Health Care of Persons with Disabilities as an Indicator of Equity in Health Systems. Open Medicine. 2011;5(1):10-12.

7. African Journal of Disability. African Network for Evidence-to-Action on Disability (AfriNEAD). Available from: http://www.ajod.org/index.php/ajod/pages/view/ historic (accessed on 29 July 2013).

8. EquitAble. EquitAble: Enabling Universal and Equitable Access to Healthcare for Vulnerable People in Resource Poor Settings in Africa. Available from: http://www.equitableproject.org (accessed on 29 July 2013).

9. World Health Organization (WHO), United Nations Educational, Scientific and Cultural Organization as those of the Australian Government National Health and Medical Research Council [40] and the Economic and Social Research Council (ESRC) [41], is needed to generate a representative, comparable and robust evidence-base over the next decade; one in which people with disabilities are also among the researchers.

\section{Conflict of interest}

The authors declare that no conflict of interest exists.

(UNESCO), International Labour Organization (ILO), International Disability and Development Consortium (IDDC). Community-Based Rehabilitation: CBR Guidelines. Geneva, Switzerland: WHO; 2010. Available from: http://www.who.int/disabilities/cbr/guide lines/en/index.html (accessed on 29 July 2013).

10. The Lancet. The Bamako Call to Action: Research for Health. Lancet. 2008;372(9653):1855.

11. World Health Organization, World Bank. World Report on Disability. Geneva, Switzerland: WHO; 2011. Available from: http://whqlibdoc.who.int/publica tions/2011/9789240685215_eng.pdf (accessed on 29 July 2013).

12. United Nations Children's Fund (UNICEF). The State of the World's Children 2013: Children with Disabilities. New York, NY, USA: UNICEF; 2013. Available from: http://www.unicef.org/sowc2013/files/ SWCR2013_ENG_Lo_res_24_Apr_2013.pdf (accessed on 29 July 2013).

13. Lollar DJ, Crews JE. Redefining the Role of Public Health in Disability. Annual Review of Public Health. 2003;24:195-208. doi:10.1146/annurev.publ health.24.100901.140844.

14. Anderson G, Horvath J. The Growing Burden of Chronic Disease in America. Public Health Reports. 2004;119(3):263-270. doi:10.1016/j.phr.2004.04.005.

15. Oeffinger KC, Eshelman DA, Tomlinson GE, Buchanan GR. Programs for Adult Survivors of Childhood Cancer. Journal of Clinical Oncology. 1998;16(8): 2864-2867.

16. Siegel K, Venkat Narayan KM. The Unite for Diabetes Campaign: Overcoming Constraints to Find a Global Policy Solution. Globalization and Health. 2008; 4(3). doi:10.1186/1744-8603-4-3.

17. Sinclair AJ. Diabetes, Disability and Frailty-A Need for Greater Recognition and Focused Research. British Journal of Diabetes \& Vascular Disease. 2012; 12(3):109. doi:10.1177/1474651412450593.

18. Cameron DL, Nixon S, Parnes P, Pidsadny M. Children with Disabilities in Low-Income Countries. Paediatrics \& Child Health. 2005;10(5):269-272.

19. Myezwa H, Stewart A, Musenge E, Nesara P. Assessment of HIV-Positive In-Patients Using the International Classification of Functioning, Disability and Health (ICF) at Chris Hani Baragwanath Hospital, Johannesburg. African Journal of AIDS Research. 2009;8(1):93-105. 
20. Groce NE, Rohleder P, Eide AH, MacLachlan M, Mall S, Swartz L. HIV Issues and People with Disabilities: A Review and Agenda for Research. Social Science \& Medicine. 2013;77:31-40. doi:10.1016/j.soc scimed.2012.10.024.

21. MacLachlan M, Khasnabis C, Mannan H. Inclusive Health. Tropical Medicine \& International Health. 2012;17(1):139-141.

22. Amin M, MacLachlan M, Mannan H, El Tayeb S, El Khatim A, Swartz L, Munthali A, Van Rooy G, McVeigh J, Eide A, Schneider M. EquiFrame: A Framework for Analysis of the Inclusion of Human Rights and Vulnerable Groups in Health Policies. Health \& Human Rights. 2011;13(2):1-20.

23. Mannan $H$, Amin $M$, MacLachlan $M$. The EquitAble Consortium. The EquiFrame Manual. Dublin, Ireland: The Global Health Press; 2011. Available from: http://www.sintef.no/Projectweb/Equitable/WP2 --Review-and-Analysis-of-Health-Policies/The-EquiFra me-Manual (accessed on 29 July 2013).

24. Turnbull HR, Wilcox BL, Stowe MJ, Umbarger GT. Matrix of Federal Statutes and Federal and State Court Decisions Reflecting the Core Concepts of Disability Policy. Journal of Disability Policy Studies. 2001; 12(3):144-176. doi:10.1177/104420730101200303.

25. MacLachlan M. Community Based Rehabilitation and Inclusive Global Health: A Way Forward. Statement to the United Nations Commission for Social Development, New York, 2 February 2012. New York, NY, USA: United Nations; 2012. Available from: http://search.un.org/search?ie=utf8\&site=un_org\&ou tput=xml_no_dtd\&client=UN_Website_en \&num $=10 \&$ l r=lang_en\&proxystylesheet=UN_Website_en\&oe=utf8 $\& q=$ maclachlan $\% 2 C+$ malcolm $\&$ Submit $=$ Go (accessed on 29 July 2013).

26. MacLachlan M, Amin M, Mannan H, El Tayeb S, Bedri N, Swartz L, Munthali A, Van Rooy G, McVeigh J. Inclusion and Human Rights in Health Policies: Comparative and Benchmarking Analysis of 51 Policies from Malawi, Sudan, South Africa, and Namibia. PLoS ONE. 2012;7(5):e35864. doi:10.1371/journal.pone.00 35864.

27. Wazakili M, Massah B, Mji G, MacLachlan M. Did What? Research Project in Brief: A-PODD (African Policy on Disability and Development) in Malawi. Dublin, Ireland: The Global Health Press; 2011. Available from: http://global-health.tcd.ie/docs/In_Brief_APODD_in_Malawi\%20\%20PDF\%2018\%20Nov.pdf (accessed on 29 July 2013).

28. Trani J-F, Browne J, Kett M, Bah O, Morlai T, Bailey N, Groce N. Access to Health Care, Reproductive Health and Disability: A Large Scale Survey in Sierra Leone. Social Science \& Medicine. 2011;73(10): 1477-1489. doi:10.1016/j.socscimed.2011.08.040.

29. Eide $A H$, Loeb $M E$, editors. Living Conditions among People with Activity Limitations in Zambia: A National Representative Study (SINTEF Report). Blindern, Oslo: SINTEF Health Research; 2006. Available from: http://www.sintef.no/upload/Helse/Lev
ek\%C3\%A5r\%20og\%20tjenester/ZambiaLCweb.pdf (accessed on 29 July 2013).

30. Mannan H, Boostrom C, Maclachlan M, McAuliffe E, Khasnabis C, Gupta N. A Systematic Review of the Effectiveness of Alternative Cadres in Community Based Rehabilitation. Human Resources for Health. 2012;10(1):20. doi:10.1186/1478-4491-10-20.

31. World Health Organization Maximizing Positive Synergies Collaborative Group. An Assessment of Interactions between Global Health Initiatives and Country Health Systems. Lancet. 2009;373(9681):21372169. doi:10.1016/S0140-6736(09)60919-3.

32. MacLachlan M, Mannan H, McAuliffe E. Staff Skills not Staff Types for Community-Based Rehabilitation. Lancet. 2011;377(9782):1988-1989. doi:10.101 6/S0140-6736(10)61925-3.

33. Gallagher $\mathrm{P}$, MacLachlan $\mathrm{M}$. Thinking through Enabling Technologies: Guidelines for Development and Implementation. In: MacLachlan M, Gallagher $\mathrm{P}$, editors. Enabling Technologies: Body Image and Body Function. Edinburgh, Scotland: Churchill Livingstone; 2004. pp. 259-264.

34. Borg J. Assistive Technology, Human Rights and Poverty in Developing Countries: Perspectives Based on a Study in Bangladesh. Lund, Sweden: Lund University; 2011. Available from: http://lup.lub.lu.se/ luur/download?func $=$ downloadFile\&recordOId $=17638$ 55\&fileOId=1766394 (accessed on 29 July 2013).

35. Handicap International, London School of Hygiene and Tropical Medicine, International Centre for Eye Health. Access to Services for Persons with Disabilities in Challenging Environments. Lyon, France: Handicap International; 2010. Available from: http:// www.handicap-international.fr/fileadmin/documents/ publications/AccessToServicesAmman.pdf (accessed on 29 July 2013).

36. Evidence Aid. Evidence Aid: Providing resources for decision-makers before, during and after disasters and other humanitarian emergencies. Available from: http://www.evidenceaid.org (accessed on 29 July 2013).

37. United Nations Enable. Disability, Natural Disasters and Emergency Situations. Available from: http://www.un.org/disabilities/default.asp?id=1546 (accessed on 29 July 2013).

38. World Health Organization. Closing the Gap: Policy into Practice on Social Determinants of Health. Discussion paper: Annex 2. Proceedings of the World Conference on Social Determinants of Health, Rio de Janeiro, Brazil, 19-21 October 2011. Geneva, Switzerland: WHO; 2011. Available from: http://www.socialprotection.org/gimi/gess/RessShowRessource.do? ressourceId=27141 (accessed on 29 July 2013).

39. Madans JH, Loeb ME, Altman BM. Measuring Disability and Monitoring the UN Convention on the Rights of Persons with Disabilities: The Work of the Washington Group on Disability Statistics. BMC Public Health. 2011; 11(4):1-8. doi:10.1186/1471-2458-11-S4-S4.

40. Australian Government National Health and Med- 
ical Research Council. Centres of Research Excellence (CRE). Canberra, Australia: NHMRC; 2013. Available from: http://www.nhmrc.gov.au/grants/apply-funding/cen tres-research-excellence-cre (accessed on 29 July 2013).

41. Economic and Social Research Council. Centres and Large Grants Competition. Swindon, UK: ESRC; 2013. Available from: http://www.esrc.ac.uk/fundingand-guidance/funding-opportunities/3672/Centres_an d_Large_Grants_competition.aspx (accessed on 29 July 2013). 